\title{
EDUCATION AND SELF-MANAGEMENT FOR PEOPLE NEWLY DIAGNOSED WITH TYPE 2 DIABETES: A QUALITATIVE STUDY OF PATIENTS' VIEWS
}

Elizabeth Ockleford, ${ }^{1}$ Rachel L. Shaw, ${ }^{2}$ Janet Willars ${ }^{1}$, Mary Dixon-Woods ${ }^{1}$

1. Social Science Group, Department of Health Sciences, University of Leicester.

2. School of Life \& Health Sciences, Aston University.

Corresponding author: Elizabeth Ockleford, Department of Health Sciences, University of Leicester, 22-28 Princess Road West, Leicester, LE1 6TP, UK. Tel: +44(0)116 2525420, emo1@leicester.ac.uk.

Final version published as: Ockleford, E., Shaw, R.L., Willars, J. \& Dixon-Woods, M. (2008). Education and self-management for people newly diagnosed with type 2 diabetes: a qualitative study of patients' views. Chronic Illness, 4, 28-37. DOI: 


\section{Abstract}

Objectives: We explored the perceptions, views and experiences of diabetes education in people with type 2 diabetes who were participating in a UK randomised controlled trial of methods of education. The intervention arm of the trial was based on DESMOND, a structured programme of group education sessions aimed at enabling self-management of diabetes, while the standard arm was usual care from general practices.

Methods: Individual semi-structured interviews were conducted with 36 adult patients, of whom 19 had attended DESMOND education sessions and 17 had been randomised to receive usual care. Data analysis was based on the constant comparative method.

Results: Four principal orientations towards diabetes and its management were identified: 'resisters', 'identity resisters, consequence accepters' 'identity accepters, consequence resisters' and 'accepters'. Participants offered varying accounts of the degree of personal responsibility that needed to be assumed in response to the diagnosis. Preferences for different styles of education were also expressed, with many reporting that they enjoyed and benefited from group education, though some reported ambivalence or disappointment with their experiences of education. It was difficult to identify striking thematic differences between accounts of people on different arms of the trial, though there was some very tentative evidence that those who attended DESMOND were more accepting of a changed identity and its implications for their management of diabetes.

Discussion: No one single approach to education is likely to suit all people newly diagnosed with diabetes, though structured group education may suit many. This paper identifies varying orientations and preferences of people with diabetes both towards forms of education and self-management, which should be taken into account when planning approaches to education.

Keywords: type 2 diabetes, qualitative research, diabetes self-management.

Final version published as: Ockleford, E., Shaw, R.L., Willars, J. \& Dixon-Woods, M. (2008). Education and self-management for people newly diagnosed with type 2 diabetes: a qualitative study of patients' views. Chronic Illness, 4, 28-37. DOI: 
Final version published as: Ockleford, E., Shaw, R.L., Willars, J. \& Dixon-Woods, M. (2008).

Education and self-management for people newly diagnosed with type 2 diabetes: a qualitative study of patients' views. Chronic Illness, 4, 28-37. DOI:

$10.1177 / 1742395307086673$ 


\section{Introduction}

Increasing prevalence of diabetes is a worldwide problem; the World Health Organisation (WHO) estimates that more than 180 million people have diabetes across the world and that this is likely to double by 2030. Reasons for the increase in prevalence include excess body weight and physical inactivity. ${ }^{1}$ There are 2.35 million people in England alone with diabetes, estimated to increase to 2.5 million by 2010 . $^{2}$ Deaths associated with diabetes currently occur most often in low or middle income countries, though the WHO projects that such deaths in upper-middle income countries are likely to rise by $80 \%$ between 2006 and $2015 .{ }^{1}$

The UK National Service Framework (NSF) for diabetes emphasises the importance of patient information from the point of diagnosis onwards, and proposes that education should involve a structured programme for people who have been newly diagnosed. ${ }^{2}$ This emphasis on promoting partnership in diabetes management is also encouraged by the National Institute for Clinical Excellence (NICE) ${ }^{3}$ guidance, which recommends that all patients receive structured education at initial diagnosis and then on a regular basis according to need. Specific advice for diabetes thus conforms to the more general principles of patient information and self-management advocated by the 'Expert Patients' programme ${ }^{4}$ and the government White Paper Choosing Health. ${ }^{5}$

In this context, how best to provide structured education and information to people with diabetes is an important question. The NICE guidance acknowledges that there is limited evidence to date to suggest which approach is most appropriate. In particular, there is considerable debate about whether group-based education offers significant advantages over individual education, with some studies suggesting that the group approach is as effective as individual education, and that it may allow a more efficient and cost-effective mode of delivery. ${ }^{6} 789$

DESMOND (Diabetes Education and Self-Management for Ongoing and Newly Diagnosed) is a structured, group-based educational programme that aims to educate patients about type 2 diabetes, provide resources for them to manage their disease, and offer a group-based opportunity to meet and share experiences with others in the same situation (see Box 1). ${ }^{10}$ Development of DESMOND involved a multidsciplinary, multicentre collaborative team which agreed upon a core set of philosophical principles that cohered about the use of 'informed choice' as the key to 'empowerment', and drew on three theoretical approaches: The Common Sense Model of Illness, Social Learning Theory, and use of a discovery learning

Final version published as: Ockleford, E., Shaw, R.L., Willars, J. \& Dixon-Woods, M. (2008). Education and self-management for people newly diagnosed with type 2 diabetes: a qualitative study of patients' views. Chronic IIIness, 4, 28-37. DOI: 
process. ${ }^{11}$ DESMOND has been evaluated in a randomised controlled trial comparing the DESMOND with current usual primary care education for diabetes. 'Usual' care varies from practice to practice, and may include group-based education or one-to-one education which varies in terms of length, content, and style. In this paper, we report a qualitative study in which we aimed to explore perceptions, views and experiences of diabetes education in people randomised to both arms of the trial.

\section{Box 1: The DESMOND randomised controlled trial}

The DESMOND (Diabetes Education and Self-Management for Ongoing and Newly Diagnosed) intervention is a structured programme of education for people newly diagnosed with Type 2 diabetes. It was developed by a multi-disciplinary team and its development was explicitly theoretically informed. ${ }^{11}$

A trial of DESMOND began in 2004. The study design is a cluster randomised controlled trial based in 17 primary care organisations (PCOs) across England and Scotland. Randomisation was at the practice level. Participants were recruited to the trial within 4 weeks of diagnosis.

Within participating PCOs, practices in the intervention arm of the trial ran DESMOND group education sessions that were attended by consenting patients within three months of their being diagnosed with type 2 diabetes. The DESMOND programme has the following characteristics:

- provides six hours of group-based structured education using a formally specified curriculum

- the six hours can be provided either as a one-day course or over two half-days, and is delivered by two healthcare professionals who have attended a formal training programme as DESMOND educators

- groups consist of 6-10 people newly diagnosed with diabetes

- people attending the group may choose to be accompanied by a partner, family member or friend

- people attending the group are given specially developed educational material

DESMOND sessions are interactive and the educators are trained to promote a non-didactic approach. As well as providing practical information about diet, activity and goal-setting and self-management of diabetes, the sessions are intended to encourage individuals to share with the group their own experiences of being diagnosed diabetic.

In the control arm, consenting patients received their practice's usual care for diabetes. 'Usual care' is not standardised across practices. In many cases this might include a group-based educational intervention, but might also involve one-to-one counselling with a specialist diabetes nurse or some other form of education.

Final version published as: Ockleford, E., Shaw, R.L., Willars, J. \& Dixon-Woods, M. (2008). Education and self-management for people newly diagnosed with type 2 diabetes: a qualitative study of patients' views. Chronic Illness, 4, 28-37. DOI: 


\section{Methods}

Approval from Huntingdon Research Ethics Committee to conduct the qualitative study was granted. Five Primary Care Organisations (PCOs) where the DESMOND trial was in progress were sampled purposively in order to engage participants from a range of geographical areas. Invitations to take part in the qualitative study were sent by the local DESMOND trial coordinators to people who had consented to take part in the trial. All those who expressed interest in the qualitative study were contacted by telephone by either EO or JW to arrange appointments for interviews. All those who volunteered were interviewed in their own homes or another location nominated by them; none withdrew having agreed to be interviewed. Invitations continued to be issued until an appropriately diverse sample had been recruited. Participants were interviewed within six months of their diagnosis with diabetes.

Semi-structured interviews using prompt guides developed following literature review and discussions within the project team were conducted face-to-face by EO and JW. Topics covered included patients' experiences of being diagnosed with diabetes, the sources of information which they had used and their views on them, and their feelings about how the condition was affecting their lives and their relationships with healthcare professionals. Interviews were recorded using a digital voice recorder and were transcribed verbatim.

Data analysis was based on the constant comparative method. ${ }^{12}$ Initially, 'open' codes to describe each unit of meaning were generated by the research team. Through comparison across transcripts, the open codes were developed into higher order thematic categories and sub-categories to provide a coding framework. This was used by EO, assisted by QSR N6 software,${ }^{13}$ to code the data. EO continually checked and modified the framework categories to ensure an adequate 'fit' with the data and MDW independently validated the assignment of the data to the categories.

\section{Results}

Interviews lasted up to one hour and were conducted with 36 people with diabetes. Of these, 19 patients had attended DESMOND education sessions and 17 had been randomised to receive standard care. Eighteen patients were male (8 intervention and 10 control) and 18 female (11 intervention, 7 control), and represented a range of ages and socio-economic groups. Most (33) were ethnically White British.

Final version published as: Ockleford, E., Shaw, R.L., Willars, J. \& Dixon-Woods, M. (2008). Education and self-management for people newly diagnosed with type 2 diabetes: a qualitative study of patients' views. Chronic Illness, 4, 28-37. DOI: 


\section{Diabetic identity}

Previous work in the area of chronic illness has demonstrated the impact of diagnosis on people's identity. ${ }^{14}$ Our analysis of the accounts offered by participants suggested that four types of response to the diagnosis could heuristically be distinguished (see Box 2).

Box 2: Responses to diagnosis

'Accepters' : those whose accounts suggested that they fully accepted the diabetic identity and its consequences

'Identity accepters, consequence resisters' : those who accepted the identity but were resistant to accepting the full implications of having diabetes

'Identity resisters, consequence accepters' : those who rejected a diabetic identity but nonetheless made considerable changes

'Resisters' : those who rejected both the identity and the consequences

\section{'Accepters'}

Participants whom we categorised as 'accepters' reported that they had fully incorporated the diabetic identity as they perceived it had been defined for them by medicine, and were enthusiastic or committed to changing their behaviour in response. Of the 19 patients we interviewed in the DESMOND arm of the trial, we deemed 14 to be 'accepters'. Of the 17 patients in the control arm, 10 were deemed 'accepters', and seven of these had attended a group education session of some kind.

Final version published as: Ockleford, E., Shaw, R.L., Willars, J. \& Dixon-Woods, M. (2008). Education and self-management for people newly diagnosed with type 2 diabetes: a qualitative study of patients' views. Chronic Illness, 4, 28-37. DOI: 
'It's had a phenomenal impact on our lives actually I mean it's, how can you describe it? I'm eating more healthily, I'm more active and just generally I mean I feel a lot better. It, I think it's woken me up to sort of living life more fully and same with my wife. I've never realised there's so much nice food around.' (INTERVENTION EO2 'accepter')

‘...it's just take it seriously, take medication, look at the way I live. Just generally take it as a big flashing light. So yeah. Er ... the only thing that it's really impacted on me is that I've changed my diet quite a lot ... which has an impact on my lifestyle ... but I was changing my diet anyway.' (CONTROL EO3 'accepter')

Although 'accepters' did accept the need for change, not all reported that they consistently adhered to what they understood to be best practice in managing their diabetes.

\section{'Identity accepters, consequence resisters'}

Participants in this category (4 intervention and 2 controls) did accept that they had diabetes, but reported that they had difficulties in embracing the full consequences of this new identity, at least as specified for them by medical orthodoxy. They produced accounts in which they argued that other aspects of their lives had higher priority than managing diabetes, and that their approach to managing their diabetes had to be understood within a broader context.

'I was so depressed.... it's all revolving round yourself you know I mean diet, diet most of time you think, "Oh god it's time now for food". And then you think, "Oh god I didn't monitor my blood" er, the thing pricking the finger you know it takes so much effort you know in between especially if you've got family ... got to give yourself time for yourself, but otherwise you just neglect your monitoring ... And that's why [I'm] unhappy about it.' (INTERVENTION JW3 'identity accepter, consequence resister')

'It's like yes I know I should pack up smoking, but the situation I'm in at the moment, I think I'd go mental.' (CONTROL EO8 'identity accepter, consequence resister')

\section{'Identity resisters, consequence accepters'}

This group of participants ( 0 intervention, 3 controls) reported that they found it difficult to accept that they had diabetes, but nonetheless described making changes to diet and lifestyle in response to the diagnosis.

'I mean I think I'm an impostor ... because I don't believe I've got diabetes at all but anyway so but what I have done is taken her advice and stopped drinking draught beers and I'm drinking these bottled things.' (CONTROL EO1 'identity rejecter, consequence accepter')

Final version published as: Ockleford, E., Shaw, R.L., Willars, J. \& Dixon-Woods, M. (2008). Education and self-management for people newly diagnosed with type 2 diabetes: a qualitative study of patients' views. Chronic Illness, 4, 28-37. DOI: 


\section{'Resisters'}

Participants whom we classified as 'resisters' ( 1 intervention, 2 controls) found it difficult to accept that they had diabetes, reporting that they did not feel any different from how they had felt before diagnosis. These participants described themselves as not making any changes either to their identity or to their lifestyle.

'And to be honest I don't feel as if I've got diabetes ... the only reason I know I've got diabetes is because the doctor told me I have. ... I don't feel as if I've got to do anything to correct it. Really I might as well carry on with my beer. I mean if I were, really took to mind that I'd got diabetes I'd do something more drastic about it. I'd flipping starve myself or something like that, force myself to go out for walks and ... But I'm not aware and I'm not fully aware of it.' (CONTROL JW5 'resister')

I'm just gonna carry on the way I've been going on.' (INTERVENTION JW6 'resister')

There is some tentative evidence here that although participants in the two arms of the trial produced mostly similar accounts, there was perhaps more 'acceptance' among the DESMOND participants. Only 5 of the 19 intervention participants were not 'accepters', while 7 of the 17 controls, including 5 of the 12 who had attended group education, were not 'accepters'. However, further research would be required to confirm this suggestion.

\section{Moral character}

Many participants in this study appeared to associate the diagnosis of diabetes with a particular moral orientation, and offered varying accounts of the degree of personal responsibility that needed to be assumed in response to the diagnosis. Participants often offered an account of their positioning in relation to what they perceived as the moral order governing their illness and the proper behaviour of those with that illness. However, the claims they made were rarely completely consistent within a single account, suggesting some struggles with moral identity. We heuristically distinguished accounts as overall indicating 'adherence' and 'lapsing' (Box 3).

\section{Box 3: Accounts of adherence and lapsing}

'Adherents' were those patients whose accounts, when we assessed the number of units of text that indicated adherence or resistance to what they perceived as the recommended regime, showed a preponderance of units indicating adherence (4 control and 8 intervention). However, only three of these ( 1 control, 2 intervention) described full adherence, with no reference to breaching what they perceived as recommended practice in relation to diabetes.

Final version published as: Ockleford, E., Shaw, R.L., Willars, J. \& Dixon-Woods, M. (2008). Education and self-management for people newly diagnosed with type 2 diabetes: a qualitative study of patients' views. Chronic Illness, 4, 28-37. DOI: 
'Lapsers', a group where all or a preponderance of references to moral responsibility described having difficulties with adherence (11 control and 10 intervention). These could be further distinguished into those who were:

'Occasional defaulters', whose references to defaulting were predominantly to temporary or occasional lapses.

'Permanent defaulters', who described themselves as more permanently unable or unwilling to adhere to what they perceived as recommended regimens.

It was not possible to classify the remaining four participants as to adherence or lapsing.

\section{'Adherents'}

The 12 patients we classified as 'adherents' argued that complete adherence to what they saw as recommended practice was 'the best policy', often referring explicitly to the clinical and social consequences of poor control for their future health. Though most (10) participants that we classified as 'adherents' were also 'accepters', this category also included two participants who, though they accepted the consequences of the diabetic identity, were not classified as full 'accepters'. (Table 1 )

I'm doing as I'm told because I think that's the best policy rather than argue or try to wriggle out of anything.' (CONTROL JW6 'accepter')

'now I'm knowing that I can't do that anymore I have actually got to make an effort and do lose the weight and exercise and stuff like that so that's in my head all the time. You've got to do this 'cos if you don't do it who the hell's gonna look after you in your old age? So hence you get on with it and that's your diabetes.'

(INTERVENTION EO5 'accepter')

\section{Lapsers}

'Acceptance' of the diabetic identity and its consequences was clearly not sufficient to ensure consistent and complete adherence, as illustrated in Table 1. Many of the 21 participants in the 'lapser' category spoke of lapses from recommended regimens as sporadic occurrences, often in response to 'special occasions'. These 11 'occasional lapsers' were usually people who had accepted the 'diabetic identity' and the consequences of this; they were explicit in recognising the possible implications of lapses for their health. They made frequent use of terms such as 'good' and 'naughty' in offering these accounts, and implied that the consequences took the form of punishments, or else they justified any aberration by appealing to the special contingencies of situations in which they lapsed.

‘... if we want to go out for a meal, might want to go to an Indian restaurant. I mean I love Indian food, we'll go and have one you know and have a burst as I say (laughs),

Final version published as: Ockleford, E., Shaw, R.L., Willars, J. \& Dixon-Woods, M. (2008). Education and self-management for people newly diagnosed with type 2 diabetes: a qualitative study of patients' views. Chronic Illness, 4, 28-37. DOI: 
have a good meal. But then when you come back, just watch it and you're on the right track again y' know. Long as you don't bring it home and say, "Well I'm gonna have that every night", and and then it's not doing you any good but yeah we find it fine we really do.' (INTERVENTION EO12 'accepter')

'Perhaps reaching out when I shouldn't, at the wedding for instance. I had a piece of cake - not very big it is true - and I had a half glass of wine which I shouldn't have on [named drug], it's on the instructions inside, it tells you not to have alcohol, but I had a half glass of champagne to do my bit with (laughs) and a half glass of red wine to have with my roast beef and it made me feel festive, it did me good mentally and emotionally' (CONTROL JW6 'accepter')

'... I don't go out shopping every day and buy cream cakes an' things you know ... I can walk past a cream cake, doesn't bother me but I do like a treat at weekends ... but erm ... you know I don't always have that ... I had doughnuts actually last weekend ... so they were quite nice ... with ... with custard in ... egg custard ... I fancied a doughnut so we had a doughnut each ...' (INTERVENTION EO10 'Identity accepter, consequence resister')

The other 10 participants (five control and five intervention) could be classified as more permanent defaulters; they identified themselves as 'lapsing' generally from what they saw as the recommended regime by having difficulties in making amendments to their routine lives, though these lapses were not necessarily in the form of complete defaults. People classified by us as permanent defaulters pointed to problems that interfered with their ability to make changes, but some also described simply finding the changes difficult to make because they were not enjoyable. These participants seemed much less likely to be explicit about the possible consequences of poor control of diabetes for their health.

'but I'm afraid that lapsed since I've had the bronchitis because I've been eating the biscuits in the morning and that you know' (INTERVENTION JW6 'resister')

'I ought to be doing more exercises. It's all right having a diet but if you aren't having the exercises then ... I mean there's nothing stopping me only the lack of ... doing it with somebody sort of thing you know.' (CONTROL EO4 'identity resister, consequence resister')

'... an' I was ... I mean I don't ... I must admit I don't do as much exercise as they would like you to do although I'm always on the go in the house but I mean not brisk walking that's what l'm referring to ...' (INTERVENTION EO7 'accepter')

In the transcripts of the DESMOND patients, three times as many lines of text were coded to breaches of the 'advised' life-style compared with the control patients. This perhaps provides tentative evidence of a greater acknowledgement and awareness of medically orthodox advice by DESMOND participants, although not to the point of complete adherence to it.

Final version published as: Ockleford, E., Shaw, R.L., Willars, J. \& Dixon-Woods, M. (2008). Education and self-management for people newly diagnosed with type 2 diabetes: a qualitative study of patients' views. Chronic Illness, 4, 28-37. DOI: 


\section{Experiences and views of group education}

Of the 36 participants in the study, 31 had attended some form of group-based education, with 19 attending the DESMOND programme. The majority (12 of 17) of control patients also reported receiving some form of group education as part of the care routinely offered to people newly diagnosed with diabetes through their practices. While the group education offered as part of routine care may be highly variable, the DESMOND programme is a systematised approach that discusses possibilities that enable self-management of diabetes in a group setting and is explicitly based on psychological theories of learning. ${ }^{11}$ A central tenet of this kind of group education is that patients are expected to share their experiences of being diagnosed with diabetes.

Participants expressed a range of views about their perceived candidacy or eligibility for inclusion in group sessions on invitation. Some (4) were keen to attend; others (7) were initially sceptical, fearing that the sessions would be boring, unhelpful, or patronising. Many participants (14 intervention and 6 control) described enjoying group-based learning and feeling that they benefited from it. They reported that they particularly valued the opportunity to get information and ask questions, sometimes suggesting that the experience was much better than they had anticipated.

'That was quite helpful because they had a dietician there, a podiatrist and I learned more that afternoon y'know again so, that was interesting, and I'm now going on a seven week course' (CONTROL EO2 'accepter')

'I was a bit sort of sceptical about it all at first because I think, "Oh no all these groups", I had visions of role playing and all the other sort of things (laughs) and I'm beyond that sort of thing now. But then I thought "I'll go. I'll give it a whirl and see how it goes"' (INTERVENTION JW4 'identity accepter, consequence resister')

Two control and five intervention participants, however, gave accounts which suggested that either they were ambivalent or that they did not enjoy group-based learning. Some (1 control, 3 intervention) felt that the experience added little to what they already knew.

'I don't know if I learned. I seemed to know quite a bit of the stuff they were talking about on the DESMOND thing' (INTERVENTION EO1 'accepter')

By contrast, others (two) found the amount of information presented during the group learning sessions overwhelming. Both of these patients had attended the course in a single whole day and it may be the case that two half-days might be more productive, although we have insufficient data to be clear on this.

Final version published as: Ockleford, E., Shaw, R.L., Willars, J. \& Dixon-Woods, M. (2008). Education and self-management for people newly diagnosed with type 2 diabetes: a qualitative study of patients' views. Chronic IIIness, 4, 28-37. DOI: 
'I mean it was ridiculous. Obviously they told you that much - I was there all day. ... well me, I might be thick but I could not take everything in all at once you know.'

(INTERVENTION EO8 'identity accepter consequence resister')

Analysis suggested that accounts of DESMOND group education compared with other forms of group intervention possibly differed in two ways: control patients seemed more likely to describe the experience as a form of professional-led teaching, while intervention patients appeared to emphasise peer-learning more.

'The good thing about them was that they were letting us ask questions rather than giving all the information first. They wanted us to ask the question, I think the good thing was that they have very small groups, yeah.' (INTERVENTION JW2 'accepter')

'throughout the lectures as it were... and they were very good actually, the dietician I think, one was a dietician and then lady telling us all about foot care you know how to wear the appropriate shoes and things' (CONTROL EO1 'identity resister, consequence accepter')

Fourteen (of 19) intervention and 7 (of 12 who had attended group education) control participants reported explicitly that they valued the input from other members of the groups they attended. The intervention participants often described this value in terms of sharing experiences, whereas the control participants seemed more likely to couch their comments in terms of the benefits they gained from the health professionals' answers to others group members' questions.

II knew quite a lot of what they talking about but it was still good to go there, to you know to see other people, listen to what their experience is and see if I could connect any with mine ... '(INTERVENTION EO13 'accepter')

'It was good because maybe things that you hadn't thought of they were bringing out then. It was covering more of a wider sphere because there was other people ...'(CONTROL EO6 'accepter')

The opportunity to meet others with diabetes was valued by patients who enjoyed group learning, but seeing people who were further advanced in the condition or had poorly controlled diabetes was also described as motivating some participants to achieve control.

'I mean you are a little bit different in you're diabetic aren't you, you know so you're amongst other people who've got diabetes you feel better about it you know.' (INTERVENTION EO9 'accepter')

II mean on DESMOND there was a young lady there whose ... who was diabetic, on insulin, didn't care about herself, put weight on, was losing feeling in her feet and everything else and that sort of... I don't want to be like that thank you, you know. I don't want grandkids to see me like that, put it that way you know. Looking after yourself now could avoid this in later life, so you know. It's been a real eye-opener for me, you know in my life. My life is changing, it's continuing to change, it's becoming

Final version published as: Ockleford, E., Shaw, R.L., Willars, J. \& Dixon-Woods, M. (2008). Education and self-management for people newly diagnosed with type 2 diabetes: a qualitative study of patients' views. Chronic Illness, 4, 28-37. DOI: 
more relaxed and I'm making decisions now which l've been putting off for years.' (INTERVENTION EO2 'accepter')

One control and 4 intervention participants, however, made negative points about the input from other members of the groups they had attended, commenting that other attendees were 'disruptive', 'miserable' or that one person had dominated the group with his/her personal experience which was not of general interest.

\section{'...I couldn't say I took it all in because sometimes the people asking questions they sort of disrupt the flow of things don't they you know in the middle of it.' (INTERVENTION EO7 'accepter')}

\section{Discussion}

The traditional 'sick-role' dyad, ${ }^{15}$ in which the doctor's authority and knowledge were paramount, and the patient dependent upon that, has been replaced by aspirations for a more concordant approach where patients are encouraged to be independent and proactive. ${ }^{16}$ Selfcare actions need, however, to be understood in terms of the meanings attached to them, the context in which they take place, the norms they are subject to, the power over decisionmaking available to individuals, ${ }^{17}$ and the social and emotional aspects of living with chronic illness. ${ }^{18} 19$ Our study has investigated the accounts of 36 patients who were randomised either to attend DESMOND (a structured group-based education programme) or routine diabetes education in general practice in the UK. Overall, the accounts from both groups of patients suggested that acceptance of the diabetic identity and its consequences was critical, but insufficient on its own, to subsequent behaviour change. Although acceptance of at least the consequences of diabetes seemed essential to a change in behaviour directed towards self-management, challenges of adherence to the perceived recommended regime persisted in over half of the accounts of participants. Accounts of behaviour appeared often to involve some kind of moral positioning in relation to responsibility for diabetes and tended to construct 'lapsing' in these terms.

It proved difficult to identify any striking thematic or narrative distinctions between the accounts of those who attended DESMOND and control patients, in part because many control patients had attended non-DESMOND group education. Most patients who attended group-based education described enjoying the sessions, though some were ambivalent or did not enjoy it. There were indications from our analysis that DESMOND patients may have been more likely to accept the 'diabetic identity' (though this may be a construct of the data and the study design) and that DESMOND patients experienced group learning as having

Final version published as: Ockleford, E., Shaw, R.L., Willars, J. \& Dixon-Woods, M. (2008) Education and self-management for people newly diagnosed with type 2 diabetes: a qualitative study of patients' views. Chronic Illness, 4, 28-37. DOI: 
more emphasis on peer-learning, while control patients may have tended to experience group learning more as traditional teaching. This finding suggests that DESMOND-style group learning may have some advantages over less systematised and less theoretically-informed forms of group education, especially in terms of promoting self-empowerment.

Our findings suggest that the social demands of everyday lives and the need to maintain a coherent identity and a 'normal life' are key challenges for people attempting to manage diabetes. ${ }^{20}$ As in other chronic illnesses, the diagnosis of diabetes may involve grief for a former self and a struggle to reconcile that with the 'new' self. ${ }^{14}{ }^{21}$ We found, as has been identified in previous work, that some patients with type 2 diabetes may not believe it is a serious disease with important consequences for lifestyle. ${ }^{22} 23$ Our analysis has shown that individuals' reactions to diagnosis and their subsequent acceptance or rejection of it are important in understanding how to engage newly diagnosed patients in self-management education. Those who resisted the 'diabetic identity' or resisted its consequences denied risks of possible degradation of health because they currently did not feel 'ill'. This was also implicated in their candidacy for group education - if they did not feel ill, then this appeared to influence their perceptions of the need to learn about lifestyle change or medication.

Lawton and colleagues ${ }^{22}$ conclude that the downplaying of potential complications is a mechanism that patients employ to dissociate themselves from a diabetic (or sick) identity. They further suggest that denial of having a serious disease may in turn influence the treatment routes patients choose. Rayman and Ellison ${ }^{24}$ also identify different degrees of engagement, specifically with diabetes self-management. These authors' category of 'preengaged' patients appears to be comparable to those in our study who are 'consequence resisters' and also 'lapsers'. Raman and Ellison suggest a possible trajectory from this preengaged state through 'engaged and struggling' to 'engaged and adjusting'. There is some tentative evidence in our sample that acceptance of the 'diabetic identity' may be reinforced by attendance at DESMOND-type group education, and that DESMOND attenders also seemed to have more sensitivity (though not necessarily more adherence) to the advised lifestyle for people with diabetes. These suggestions would need to be confirmed by other, larger studies, and by prospective work. It is perhaps also important to note that those who do not accept the diabetic identity may be much less likely to respond positively to an invitation to attend group education, and other strategies may be required to access these patients and persuade them of the need to recognise the implications of their altered state.

Perhaps the most important overall finding of our study is that as far as group education goes, one approach is unlikely to suit all people with diabetes. Within our sample we identified

Final version published as: Ockleford, E., Shaw, R.L., Willars, J. \& Dixon-Woods, M. (2008). Education and self-management for people newly diagnosed with type 2 diabetes: a qualitative study of patients' views. Chronic Illness, 4, 28-37. DOI: 
differing orientations towards the disease and its management, and different preferences for style of education and response to it. It will be important that this diversity is recognised in the design and implementation of educational interventions aimed at promoting self-management, both in diabetes and elsewhere.

Final version published as: Ockleford, E., Shaw, R.L., Willars, J. \& Dixon-Woods, M. (2008). Education and self-management for people newly diagnosed with type 2 diabetes: a qualitative study of patients' views. Chronic Illness, 4, 28-37. DOI: 


\section{Acknowledgements}

Thanks to The DESMOND Collaborative for funding this project. Thanks also to all the participants who volunteered.

Final version published as: Ockleford, E., Shaw, R.L., Willars, J. \& Dixon-Woods, M. (2008). Education and self-management for people newly diagnosed with type 2 diabetes: a qualitative study of patients' views. Chronic Illness, 4, 28-37. DOI: 


\section{References}

${ }^{1}$ World Health Organisation. Diabetes Factsheet, 2006. Retrieved 27 February 2007, from http://www.who.int/mediacentre/factsheets/fs312/en/index.html.

${ }^{2}$ Department of Health. Diabetes, 2007. Retrieved 27 February 2007, from http://www.dh.gov.uk/PolicyAndGuidance/HealthAndSocialCareTopics/Diabetes/fs/en.

${ }^{3}$ National Institute for Clinical Excellence. The clinical effectiveness and cost effectiveness of patient education models for diabetes Technology Appraisal No 60, 2003. Retrieved 19 June 2007, from http://guidance.nice.org.uk/TA60

${ }^{4}$ Expert Patients Programme. Retrieved 6 June 2007, from http://www.expertpatients.co.uk/public/default.aspx

${ }^{5}$ Department of Health. Choosing health: making healthy choices easier, 2004. Retrieved 19 June 2007 from

http://www.dh.gov.uk/en/Publicationsandstatistics/Publications/PublicationsPolicyAndGuidanc e/DH 4094550

${ }^{6}$ Rickheim PL, Weaver TW, Flader JL, Kendall DM. Assessment of group versus individual diabetes education: a randomized study. Diabetes Care 2002; 25(2): 269-274

${ }^{7}$ Barlow J, Wright C, Sheasby J, Turner A, Hainsworth J. Self-management approaches for people with chronic conditions: a review. Patient Education \& Counseling 2002; 48: 177-187

${ }^{8}$ Alderson M, Starr L, Gow S, Moreland J. The program for rheumatic independent selfmanagement: a pilot evaluation. Clin Rheumatol 1999; 18: 283-92

${ }^{9}$ Clark NM, Becker MH, Janz NK, Lorig K, Rakowski W, Anderson L. Self-management of chronic disease by older adults: a review and questions for research. J Aging Health 1991; 3: 3-27

${ }^{10}$ DESMOND . Structured education for people with type 2 diabetes. Retrieved 19 June 2007, from http://www.cgsupport.nhs.uk/downloads/NDST/Providing DESMOND info.pdf

${ }^{11}$ Skinner TC, Carey ME, Cradock S, Daly H, Davies MJ, Doherty Y, Heller S, Khunti K, Oliver L. Diabetes education and self-management for ongoing and newly diagnosed (DESMOND): Process modelling of pilot study. Patient Education and Counseling 2006; 64: 369-377

Final version published as: Ockleford, E., Shaw, R.L., Willars, J. \& Dixon-Woods, M. (2008). Education and self-management for people newly diagnosed with type 2 diabetes: a qualitative study of patients' views. Chronic Illness, 4, 28-37. DOI: 
${ }^{12}$ Glaser BG, Strauss AL. The discovery of grounded theory: strategies for qualitative research. Chicago: Aldine, 1967

${ }^{13}$ QSR International N6. 2002, http://www.qsrinternational.com/products previousproducts n6.aspx

${ }^{14}$ Bury M. Chronic illness as biographical disruption. Sociology of Health and IIIness1982; 4: $167-182$

${ }^{15}$ Parsons T. The social system. Glencoe, IL: The Free Press of Glencoe, 1951

${ }^{16}$ Crossley M. 'Sick role' or 'empowerment'? The ambiguities of life with an HIV positive diagnosis. Sociology of Health \& IIIness 1998; 20(4): 507-531

${ }^{17}$ Maclean HM. Patterns of diet related self care in diabetes. Social Science and Medicine 1991; 32: 689-696

${ }^{18}$ May C. Chronic illness and intractability: professional-patient interactions in primary care. Chronic Illness 2005; 1: 15-20

${ }^{19}$ Hunt LM, Jordan B, Irwin S. Views of what's wrong: diagnosis and patients' concepts of illness. Social Science and Medicine 1989; 28(9): 945-956

${ }^{20}$ Townsend A, Wyke S, Hunt K. Self-managing and managing self: practical and moral dilemmas in accounts of living with chronic illness. Chronic Illness 2006; 2(3): 185-194

${ }^{21}$ Bramley N, Eatough V. The experience of living with Parkinson's Disease: an interpretative phenomenological analysis case study. Psychology \& Health 2005; 20: 223-235

${ }^{22}$ Lawton J, Peel E, Parry O, Araoz G, Douglas M. Lay perceptions of type 2 diabetes in Scotland: bringing health services back in. Social Science \& Medicine 2005; 60: 1423-1435

${ }^{23}$ Murphy E, Kinmonth AL. No symptoms, no problem? Patients' understandings of noninsulin dependent diabetes. Family Practice 1995; 12: 184-192

${ }^{24}$ Rayman KM, Ellison, GC. Home alone: the experience of women with type 2 diabetes who are new to intensive control. Health Care for Women International 2004; 25: 900-915

Final version published as: Ockleford, E., Shaw, R.L., Willars, J. \& Dixon-Woods, M. (2008). Education and self-management for people newly diagnosed with type 2 diabetes: a qualitative study of patients' views. Chronic Illness, 4, 28-37. DOI: 
Table 1: Adherence and acceptance

\begin{tabular}{|l|l|l|l|l|}
\hline & Accepters & $\begin{array}{l}\text { Identity accepters, } \\
\text { consequence } \\
\text { resisters }\end{array}$ & $\begin{array}{l}\text { Identity resisters, } \\
\text { consequence } \\
\text { accepters }\end{array}$ & Resisters \\
\hline Adherents & 8 Intervention & 0 & 1 Intervention & 0 \\
\hline Lapsers & 5 Intervention & 4 Intervention & 0 & 1 control \\
& 7 Control & 2 control & 0 Intervention \\
\hline
\end{tabular}

Final version published as: Ockleford, E., Shaw, R.L., Willars, J. \& Dixon-Woods, M. (2008).

Education and self-management for people newly diagnosed with type 2 diabetes: a qualitative study of patients' views. Chronic Illness, 4, 28-37. DOI: 